\title{
Erratum to: Heat transfer and inclined magnetic field analysis on peristaltically induced motion of small particles
}

\author{
M. M. Bhatti ${ }^{1}$ A. Zeeshan ${ }^{2}$ N. Ijaz ${ }^{2} \cdot$ R. Ellahi' ${ }^{2,3}$
}

Published online: 11 April 2017

(C) The Brazilian Society of Mechanical Sciences and Engineering 2017

Erratum to: J Braz. Soc. Mech. Sci. Eng.

DOI 10.1007/s40430-017-0760-6

The original version of this article unfortunately contained a mistake. The spelling of the third author was incorrect. The correct name is N. Ijaz.

The original article was corrected.

The online version of the original article can be found under doi:10.1007/s40430-017-0760-6.

M. M. Bhatti

muhammad09@shu.edu.cn; mubashirme@yahoo.com

1 Shanghai Institute of Applied Mathematics and Mechanics, Shanghai University, Shanghai, China

2 Department of Mathematics and Statistics, International Islamic University, Islamabad, Pakistan

3 Department of Mechanical Engineering, University of California, Bourns Hall, Riverside, CA 92521, USA 